\title{
Outcomes of colorectal stents when used as a bridge to curative resection in obstruction secondary to colorectal cancer
}

\author{
Philip R Harvey ${ }^{1} \cdot$ James Rees ${ }^{1} \cdot$ Simon Baldwin ${ }^{2} \cdot$ Hina Waheed $^{2} \cdot$ Jamie-Rae Tanner $^{2} \cdot$ Felicity Evison $^{2}$.

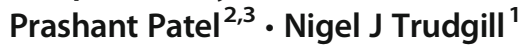

Accepted: 25 April 2019 / Published online: 7 June 2019

(C) The Author(s) 2019

\begin{abstract}
Background Up to $25 \%$ of colorectal cancers present with bowel obstruction. Metal stents (MS) can provide a bridge to surgery by relieving obstruction and allowing the subject's condition to improve pre-operatively.

Methods Hospital Episode Statistics (HES) is a database of all NHS funded secondary care episodes in England. Subjects admitted with bowel obstruction secondary to colorectal cancer without metastases were identified and subdivided into two groups: MS insertion prior to surgery and surgery only. Due to demographic differences between the groups, propensity score matching was used to analyse procedural outcomes, mortality and readmission within 30 days in left-sided cancers based upon age, sex and Charlson co-morbidity score.

Results Over 10 years, 4571 subjects were identified; 401 received a MS and 4170 underwent surgery only. Median age of MS subjects was 71 (IQR 62-79) years; 226 (56.4\%) were male. Median age of surgery-only subjects was 73 (64-81); 2165 (51.9\%) were male. Following propensity matching $375 \mathrm{MS}$ and 375 surgery-only subjects remained; MS had fewer readmissions within 30 days $(28(7.5 \%)$ versus $44(11.7 \%), p=0.047)$, fewer respiratory complications $(<6(<1.5 \%)$ versus $28(7.5 \%), p<0.001)$, lower stoma rates $(49(13.1 \%)$ versus $159(42.4 \%), p<0.001)$ and higher rates of laparoscopic surgery $(154(41.1 \%)$ versus 25 $(6.7 \%), p<0.001)$. Mortality was lower in the MS group at 30 days $(7(1.9 \%)$ versus $33(8.8 \%), p<0.001)$ and 1 year $(37(9.9 \%)$ versus $71(19.0 \%), p<0.001)$.

Conclusions In subjects presenting with obstructing colorectal cancer outcomes including respiratory complications, readmission and mortality appear to be better in subjects undergoing MS as a bridge to surgery compared to surgery alone.
\end{abstract}

Keywords Colorectal cancer $\cdot$ Bowel obstruction $\cdot$ Colonic stent $\cdot$ Colorectal surgery

Electronic supplementary material The online version of this article (https://doi.org/10.1007/s00384-019-03302-5) contains supplementary material, which is available to authorized users.

Nigel J Trudgill

nigel.trudgill@nhs.net

1 Department of Gastroenterology, Sandwell and West Birmingham Hospitals NHS Trust, Birmingham, UK

2 Department of Health Informatics, University Hospital Birmingham NHS Foundation Trust, Birmingham, UK

3 Institute of Cancer and Genomic Science, University of Birmingham, Birmingham, UK

\section{Introduction}

Colorectal cancer is the third most common form of cancer internationally [1]. A significant proportion of colorectal cancer subjects are diagnosed when they present with colorectal obstruction. This group represents between 16 and $25 \%$ of new colorectal cancer diagnoses $[2,3]$. These subjects often have advanced malignancies, poor nutritional status and usually have significantly deranged physiology at presentation. The primary treatment goal is to relieve the obstruction, usually through emergency surgery. However, such operations carry significant risks, and recently published outcome data suggest that in-hospital mortality is as high as $14 \%$ [4]. Outcomes are significantly better for non-emergency or elective resections with mortality rates of $0.7 \%$ and $3.7 \%$ reported for laparoscopic and open procedures, respectively [4]. Subjects undergoing an elective surgical procedure can be 
optimised prior to the operation. There is also more opportunity to undertake detailed staging and consult with a multidisciplinary team (MDT).

Colorectal metal stents (MS) represent an alternative to emergency surgery, relieving obstruction without the need for immediate surgical resection. This has the potential to significantly reduce the risk of resectional surgery in subjects presenting with obstruction. However, colorectal MS are not commonly used in subjects presenting with obstruction, especially in curable disease [5]. A meta-analysis of randomised control trials including a total of 273 subjects from five trials of whom 136 underwent a MS insertion prior to surgical treatment for their underlying malignancy. Although no survival benefit was found, it was demonstrated that MS subjects had fewer complications and lower stoma rates [6]. It has been suggested that although surgeons are very willing to place MS in subjects with metastatic colorectal cancer, they are less comfortable with such an approach, incorporating delayed surgery, in potentially curable disease [7].

The aim of this study was to utilise national administrative data from Hospital Episode Statistics (HES) to study a large cohort of subjects undergoing MS insertion followed by semielective curative resection in comparison with subjects undergoing immediate resectional surgery for bowel obstruction due to colorectal cancer.

\section{Methods}

\section{Hospital episode statistics}

The HES database is the administrative record of all episodes of care provided by the National Health Service (NHS) within England under the National Health Service [8]. A unique identification code allows episodes of care to be linked together for individual subjects. Information recorded within an episode includes subject demographic, diagnostic (International classification of diseases 10 (ICD10)) and procedural data (Office of Population Census and Surveys Classification of Interventions and Procedures, version 4 (OPCS4) codes) and can be linked to the Office of National Statistics (ONS) for mortality data.

\section{Inclusion and exclusion criteria}

Subjects were included if they had an ICD10 diagnosis code between January 2006 and December 2015 for an emergency admission with bowel obstruction (Appendix 1). A diagnosis code for colon cancer within 12 months prior or up to 3 months after the episode of obstruction was also required (Appendix 2). A co-existing OPCS4 code for colorectal resection (Appendix 3) at the same time or within the subsequent 12 months to the colon cancer diagnosis was also mandatory.
Subjects were included in the MS group if an OPCS4 code for colorectal MS (appendix 4) was present within 4 weeks of being admitted with obstruction. If no MS code was present, they were included in the surgery-only group.

Subjects were excluded if there was a code for metastatic disease (except lymph node metastasis) prior to surgery to ensure only those treated with curative intent were included (Appendix 5). Subjects were also excluded if they were under 18 years of age at the time of presenting with obstruction, if they were resident outside of England or of no fixed abode, as follow-up may occur outside of England and not be captured. Subjects with missing age or sex and those with a death date recorded prior to initial presentation were excluded, as this information is used to generate the unique HES patient ID. Subjects undergoing MS followed by resection more than 12 months later were also excluded.

\section{Data validation}

All subjects undergoing a MS insertion for colon cancer were identified over a 3-year period (January 2012-December 2014) at Sandwell and West Birmingham NHS trust from multiple sources including endoscopy reporting software, the radiology reporting system and individual operator logs. This was then compared to the number of MS for colon cancer in HES for the same time period for the same provider to assess the accuracy of HES data extraction for MS in colorectal cancer.

The rate of stent failure in the MS group, defined as requirement for surgical resection during the same admission as stent insertion, was compared to published studies [9].

\section{Data analysis}

Time to surgery was calculated from the date of emergency admission with obstruction to subsequent resectional surgery. When multiple colorectal surgeries were found, the surgery closest to the admission with obstruction was included with further procedures considered as re-operations.

Demographic data extraction included gender, age, ethnicity and deprivation quintile based on the Indices of Multiple Deprivation (2010) (1 being the most deprived, 5 the least deprived). The type of resection including stoma formation and if the surgical resection was during the same admission as the presentation with obstruction were also extracted from HES. A Charlson co-morbidity score was also calculated at the time of obstruction; however, cancer was excluded from this score. This scoring system has previously been validated in HES $[10,11]$. Length of stay data was collected to allow a comparison of bed days between different treatment strategies.

Following resection codes for complications (Appendix 6) were sought in HES within 30 days of discharge and the 30- 
day emergency re-admission rate. The proportion of open versus laparoscopic surgery and stoma formation was also calculated. Cases were also linked to ONS mortality data to provide 7- and 30-day mortality.

\section{Statistical analysis}

Statistical analysis was performed using STATA version 14 [12]. Univariable analyses were performed utilising Chisquared and Fishers' exact test where appropriate for categorical variables, and Mann Whitney tests for non-parametric data items. $P$ values of $<0.05$ were considered statistically significant. Values of 5 or fewer are suppressed and expressed as $<6$ in line with national guidelines on the publication of HES data.

Preliminary comparison of unmatched MS and surgeryonly groups revealed significant demographic differences, and therefore, propensity score matching was performed. The user written program "PSMATCH2" in STATA was used to pair each MS subject to a surgery-only subject [13]. Subjects with similar propensity scores were selected using 1:1 nearest-neighbour matching with calliper width of 0.001 and no replacement. Each pair was used once and unpaired cases were excluded from further analysis. Subjects with a transverse or non-extended right hemicolectomy were excluded from propensity score matching as they were unlikely to be managed with a MS. The matching model included gender, age at obstruction, resection type and Charlson co-morbidity score. Once matched, the remaining included subject outcomes, including mortality and complications, were compared using univariable analysis. Kaplan-Meier graph of matched cohorts was constructed for 1-year survival and compared using log-rank test.

\section{Results}

\section{Data validation}

Between 2012 and the end of 2014 at Sandwell and West Birmingham Hospitals NHS Trust, 27 MS were inserted for obstruction secondary to cancer. Over the same time period, 25 were coded within HES as undergoing MS for obstruction secondary to colorectal cancer, giving a $92.6 \%$ concordance.

The CREST study (randomised phase III study of stenting as a bridge to surgery in obstructing colorectal cancer-results of the UK ColoRectal Endoscopic Stenting Trial), currently published in abstract form only, provides further opportunity for validation [9]. Stenting success was reported in the trial as $82 \%$ compared to $86.5 \%$ in the current study. Similarly, the largest meta- analysis reported technically successful stent placement in $88.5 \%$ in 1061 subjects [14].

\section{Subject demographics (un-matched)}

There were 4571 subjects who met the inclusion criteria, of whom 401 underwent MS insertion, from an initial group of 32,039 (793 MS) who presented with bowel obstruction between 2006 and 2015 secondary to colorectal cancer. Reasons for exclusions are shown in Fig. 1.

The study subject demographics are described in Table 1. In the whole study population, the surgery-only group was numerically older (73(IQR 64-81 versus 71 (63-79) years) and less likely to have no co-morbidities recorded $(64.6 \%$ versus $69.8 \%, p=0.005$ ). There appeared to be no statistically significant differences in sex, deprivation or ethnicity.

The most common initial surgical resection in the MS group was rectal operations $(174,43.4 \%)$ or left hemicolectomy $(119,29.7 \%)$. Subjects undergoing surgery only were most likely to have a right hemicolectomy (1808, $43.4 \%)$ followed by rectal surgery $(913,21.9 \%)(p<0.001)$.

\section{Propensity matched analysis}

Following propensity matching 375 MS were paired to 375 surgery-only subjects for analysis. Univariable comparison of Charlson scores $(p=0.960)$, age $(p=0.997)$, gender $(p=$ $0.941)$ and resection type $(p=1.0)$ no longer revealed a statistical difference between the groups.

Subgroup demographics of propensity-matched subjects undergoing conservative management (no resection or stent during index admission) for bowel obstruction demonstrate that this cohort has less co-morbidity compared to those undergoing stent placement or surgery only (full data presented in appendix 7).

\section{Procedure outcomes following propensity matching}

The MS procedure appeared to have a similarly high degree of technical success in the matched cohort with 330 $(88.0 \%)$ subjects not requiring a resection during the initial admission with obstruction (Table 2). In the surgery-only group, $104(27.7 \%)$ subjects did not require surgical resection at the time of presentation with obstruction. This is likely to represent successful conservative management. Median time to resection in the MS group following presentation with obstruction was 32 days and 3 days in the surgery-only group. Subjects were more likely to have a laparoscopic resection following MS (41.1\%) compared to the surgery-only group $(6.7 \%, p<0.001)$. MS subjects were also less likely to be left with a stoma $(13.1 \%)$ than surgery-only group subjects $(42.4 \%, p<0.001)$. 
Fig. 1 Study flow chart

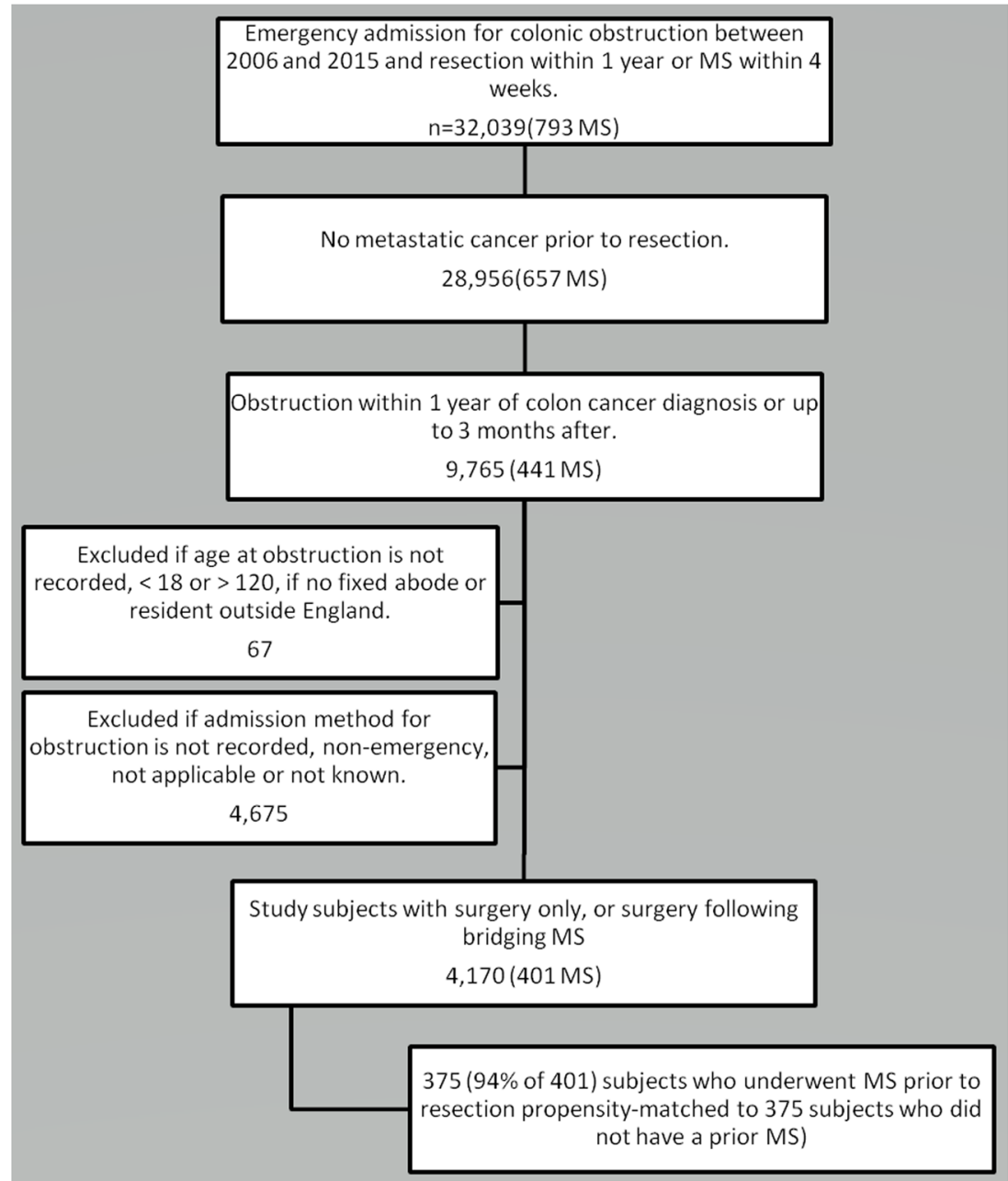

\section{Mortality and complications after resection following propensity matching}

Univariable analyses following propensity matching demonstrated that subjects in the MS group had lower 30 -day mortality compared to the surgery-only group (7 (1.9\%) versus 33 $(8.8 \%), p<0.001)$ and lower 1-year mortality (37 (9.9\%) versus $71(18.9 \%)$ ) (Table 2). The difference in mortality at 1 year is shown in a Kaplan-Meier chart (Fig. 2).

At 30 days, readmission rates were higher following surgery only compared to MS $(7.5 \%$ versus $11.7 \%, p=0.047)$. Respiratory complications were also significantly lower in the MS group $(p<0.001)$ (Table 3$)$.

\section{Discussion}

Following propensity score matching of MS and surgery-only subjects to control for differences in co-morbidity score and age between the groups, subjects receiving a bridging MS had significantly lower 30-day mortality $(1.9 \%)$ when compared to their surgery-only counterparts $(8.8 \%)$. Consequently, 1- year mortality was also lower for MS subjects (9.9\%) compared to the surgery group (18.9\%).

The most recent meta-analysis of colorectal MS as a bridge to surgery, including 136 bridging stents, reported that 30-day mortality after MS was $5.9 \%$ compared to $7.3 \%$ in the surgery-only group [7]. A larger meta-analysis from 2004 of non-randomised studies included 407 bridging stents and reported $0.58 \%$ 30-day mortality, albeit without a comparator surgical group without a MS [6]. In ESCO, a multicentre Italian randomised control study, 60-day mortality was reported as $7.1 \%$ and $5 \%$ for MS and surgery-only groups, respectively [13]. A preliminary report of the CReST trial describes $5.3 \%$ and $4.4 \%$ 30-day mortality for MS and surgery-only groups, respectively [9]. The present study differs from previous studies in that our sample population is larger, including $401 \mathrm{MS}$ compared to 136 in the latest meta-analysis, 56 in ESCO and 246 total randomised subjects (actual stent number not yet reported) in CReST. Furthermore, there are significant methodological differences, CReST and ESCO both report shorter times to surgery within 4 weeks and a median of 5 days, respectively. By comparison, median time to surgery was 32 (IQR 20-46) days in the present study. This is a 
Table 1 Study subject demographics in the whole study population and after propensity matching

\begin{tabular}{|c|c|c|c|c|c|c|}
\hline \multirow[t]{2}{*}{ Variables $n(\%)$} & \multicolumn{3}{|c|}{ Whole study population } & \multicolumn{3}{|c|}{ After propensity matching } \\
\hline & $\begin{array}{l}\text { Surgery only } \\
(n=4170)\end{array}$ & $\begin{array}{l}\text { Metal stent } \\
(n=401)\end{array}$ & $p$ value & $\begin{array}{l}\text { Surgery only } \\
(n=375)\end{array}$ & $\begin{array}{l}\text { Metal stent } \\
(n=375)\end{array}$ & $\begin{array}{l}p \\
\text { value }\end{array}$ \\
\hline \multicolumn{7}{|l|}{ Age in years } \\
\hline$\leq 29$ & $32(0.8)$ & - & \multirow[t]{7}{*}{0.051} & - & - & \multirow[t]{7}{*}{$0.99^{\circ}$} \\
\hline $30-39$ & $74(1.8)$ & $10(2.5)$ & & $7(1.9)$ & $9(2.4)$ & \\
\hline $40-49$ & $188(4.5)$ & $21(5.2)$ & & $20(5.3)$ & $20(5.3)$ & \\
\hline $50-59$ & $450(10.8)$ & $48(12.0)$ & & $45(12)$ & $46(12.3)$ & \\
\hline $60-69$ & $886(21.3)$ & $95(23.7)$ & & $90(24)$ & $90(24)$ & \\
\hline $70-79$ & $1345(32.3)$ & $139(34.7)$ & & $128(34.1)$ & $128(34.1)$ & \\
\hline$\geq 80$ & $1195(28.7)$ & $88(22.0)$ & & $85(22.7)$ & $82(21.9)$ & \\
\hline \multicolumn{7}{|l|}{ Sex } \\
\hline Male & 2165 (51.9) & $226(56.36)$ & \multirow[t]{2}{*}{0.089} & $211(56.3)$ & $212(56.5)$ & \multirow[t]{2}{*}{0.94} \\
\hline Female & $2005(48.1)$ & $175(43.64)$ & & $164(43.7)$ & $163(43.5)$ & \\
\hline \multicolumn{7}{|l|}{ Deprivation } \\
\hline Quintile 1 & $>720(>17.3)$ & $70(17.5)$ & \multirow[t]{6}{*}{0.963} & $66(17.6)$ & $63(16.8)$ & \multirow[t]{6}{*}{0.99} \\
\hline Quintile 2 & $798(19.1)$ & $81(20.2)$ & & $77(20.5)$ & $76(20.3)$ & \\
\hline Quintile 3 & $884(21.2)$ & $82(20.5)$ & & $76(20.3)$ & $74(19.7)$ & \\
\hline Quintile 4 & $876(21.0)$ & $87(21.7)$ & & $80(21.3)$ & $84(22.4)$ & \\
\hline Quintile 5 & $888(21.3)$ & $81(20.2)$ & & $76(20.3)$ & $78(20.8)$ & \\
\hline Unknown & $(<0.001)^{\mathrm{a}}$ & $0(0)$ & & & & \\
\hline \multicolumn{7}{|l|}{ Ethnicity } \\
\hline White & $3637(87.2)$ & $352(87.8)$ & \multirow[t]{6}{*}{0.761} & $311(82.9)$ & $328(87.5)$ & \multirow[t]{6}{*}{0.48} \\
\hline Asian & $64(1.5)$ & & & & & \\
\hline Black & $76(1.8)$ & $7(1.75)$ & & $10(2.7)$ & $7(1.9)$ & \\
\hline Mixed & $16(0.4)$ & a & & a & a & \\
\hline Other & $59(1.4)$ & a & & $8(2.1)$ & a & \\
\hline Unknown & $318(7.6)$ & $31(7.7)$ & & $39(10.4)$ & $30(8)$ & \\
\hline \multicolumn{7}{|c|}{ Charlson co-morbidity score } \\
\hline 0 & 2695 (64.6) & $280(69.8)$ & \multirow[t]{3}{*}{0.005} & $272(72.5)$ & $272(72.5)$ & \multirow[t]{3}{*}{0.96} \\
\hline $1-4$ & $690(16.6)$ & $72(18.0)$ & & $63(16.8)$ & $65(17.3)$ & \\
\hline $5+$ & $785(18.8)$ & $49(12.2)$ & & $40(10.7)$ & $38(10.1)$ & \\
\hline \multicolumn{7}{|l|}{ Surgical resection type } \\
\hline $\begin{array}{l}\text { Right } \\
\text { Hemicolectomy }\end{array}$ & $1808(43.4)$ & $>5(>1.2)^{\mathrm{a}}$ & \multirow[t]{6}{*}{$<0.001$} & $\mathrm{~b}$ & $\mathrm{~b}$ & \multirow[t]{6}{*}{0.987} \\
\hline Rectal operation & $913(21.9)$ & $174(43.4)$ & & $172(45.8)$ & $172(45.9)$ & \\
\hline $\begin{array}{l}\text { Extended right } \\
\text { hemicolectomy }\end{array}$ & $749(18.0)$ & $34(8.5)$ & & $32(8.5)$ & $34(9.1)$ & \\
\hline $\begin{array}{l}\text { Left } \\
\text { Hemicolectomy }\end{array}$ & $339(8.1)$ & 119 (29.7) & & $109(29.1)$ & $110(29.3)$ & \\
\hline $\begin{array}{l}\text { Sigmoid } \\
\text { colectomy }\end{array}$ & $316(7.6)$ & $61(15.2)$ & & $62(16.5)$ & $59(15.7)$ & \\
\hline $\begin{array}{l}\text { Transverse } \\
\text { Colectomy }\end{array}$ & $45(1.1)$ & a & & $\mathrm{b}$ & $\mathrm{b}$ & \\
\hline
\end{tabular}

${ }^{\text {a }}$ Indicates that the figure is $<6$. If a single figure is censured, another will be marked as " $>$ " reflecting a value up to 5 points higher than that stated, to ensure that the censured figure cannot be calculated

${ }^{\mathrm{b}}$ Excluded from propensity-matched groups significant difference, as one of the main arguments for using bridging MS is to facilitate a period of medical stabilisation prior to surgery. Shortening the time between resection and MS insertion will potentially reduce the benefit of MS in comparison with proceeding straight to surgery for obstruction.
Hospital Episode Statistics data provides a powerful tool to examine subject outcomes, but has a number of limitations, in particular, a lack of data regarding tumour stage (such as TNM), illness severity markers, treatment intention and other data important to outcomes. However, trials of MS in left- 
Table 2 Surgical outcomes following colon cancer resection in the whole study population and after propensity matching

\begin{tabular}{|c|c|c|c|c|c|c|}
\hline \multirow[t]{2}{*}{ Variables } & \multicolumn{3}{|c|}{ Whole study population } & \multicolumn{3}{|c|}{ After propensity-matching } \\
\hline & $\begin{array}{l}\text { Surgery only } \\
(n=4170)\end{array}$ & $\begin{array}{l}\text { Bridging metal } \\
(n=401)\end{array}$ & $p$ value & $\begin{array}{l}\text { Surgery only } \\
(n=375)\end{array}$ & $\begin{array}{l}\text { Bridging stent } \\
(n=375)\end{array}$ & $p$ value \\
\hline Obstruction episode length of stay (days) & $14(8-23)$ & $6(4-10)$ & N/A & $13(8-23)$ & $6(4-10)$ & N/A \\
\hline Time to MS insertion (days) & & $2(1-3)$ & N/A & & $2(1-3)$ & N/A \\
\hline Time to resection (days) & $2(1-9)$ & $32(20-48)$ & $<0.001$ & $3(1-14)$ & $32(20-46)$ & $<0.001$ \\
\hline Length of stay for resection (days) & $12(7-20)$ & $7(5-13)$ & $<0.001$ & $12(8-22)$ & $7(5-13)$ & $<0.001$ \\
\hline \multicolumn{7}{|l|}{ Stoma required } \\
\hline $\begin{array}{l}\text { No } \\
\text { Yes }\end{array}$ & $\begin{array}{r}3173(76.1) \\
997(23.9)\end{array}$ & $\begin{array}{r}349(87.0) \\
52(13.0)\end{array}$ & $<0.001$ & $\begin{array}{l}216(57.6) \\
159(42.4)\end{array}$ & $\begin{array}{r}326(86.9) \\
49(13.1)\end{array}$ & $<0.001$ \\
\hline \multicolumn{7}{|l|}{ Resection method } \\
\hline $\begin{array}{l}\text { Conversion to open } \\
\text { Laparoscopic } \\
\text { Open }\end{array}$ & $\begin{array}{c}108(2.6) \\
300(7.2) \\
3762(90.2)\end{array}$ & $\begin{array}{c}33(8.2) \\
166(41.4) \\
202(50.4)\end{array}$ & $<0.001$ & $\begin{array}{c}9(2.4) \\
25(6.7) \\
341(90.9)\end{array}$ & $\begin{array}{c}32(8.5) \\
154(41.1) \\
189(50.4)\end{array}$ & $<0.001$ \\
\hline \multicolumn{7}{|l|}{ Resection during admission for obstruction } \\
\hline $\begin{array}{l}\text { No } \\
\text { Yes }\end{array}$ & $\begin{array}{r}840(20.1) \\
3330(79.9)\end{array}$ & $\begin{array}{l}352(87.8) \\
49(12.2)\end{array}$ & $<0.001$ & $\begin{array}{l}104(27.7) \\
271(72.3)\end{array}$ & $\begin{array}{r}330(88) \\
45(12)\end{array}$ & $<0.001$ \\
\hline \multicolumn{7}{|l|}{ Death within 30 days of resection } \\
\hline $\begin{array}{l}\text { No } \\
\text { Yes }\end{array}$ & $\begin{array}{l}3778(90.6) \\
392(9.4)\end{array}$ & $\begin{array}{l}394(98.3) \\
\quad 7(1.8)\end{array}$ & $<0.001$ & $\begin{array}{l}342(91.2) \\
33(8.8)\end{array}$ & $\begin{array}{l}368(98.1) \\
\quad 7(1.9)\end{array}$ & $<0.001$ \\
\hline \multicolumn{7}{|l|}{ Death within 1 year of resection } \\
\hline $\begin{array}{l}\text { No } \\
\text { Yes }\end{array}$ & $\begin{array}{r}3186(76.4) \\
984(23.6)\end{array}$ & $\begin{array}{r}361(90.0) \\
40(10.0)\end{array}$ & $<0.001$ & $\begin{array}{r}304(81.1) \\
71(18.9)\end{array}$ & $\begin{array}{c}338(90.1) \\
37(9.9)\end{array}$ & $<0.001$ \\
\hline \multicolumn{7}{|l|}{ Re-admission within 30 days of resection } \\
\hline $\begin{array}{l}\text { No } \\
\text { Yes }\end{array}$ & $\begin{array}{r}3632(87.1) \\
538(12.9)\end{array}$ & $\begin{array}{c}371(92.5) \\
30(7.5)\end{array}$ & 0.002 & $\begin{array}{r}331(88.3) \\
44(11.7)\end{array}$ & $\begin{array}{l}347(92.5) \\
28(7.5)\end{array}$ & 0.047 \\
\hline
\end{tabular}

sided obstruction require a potentially unwell or unstable patient group and surveys have demonstrated clinician reluctance to use MS in the scenario of potentially curable colorectal cancer [7]. It is therefore not surprising that multicentre randomised studies of bridging MS have struggled to recruit subjects. An analysis using HES data is therefore a pragmatic method of analysing a large dataset to address questions concerning outcomes of bridging MS. Having used the HES
Fig. 2 Propensity matched Kaplan-Meier curves with 95\% confidence intervals for 1-year survival post-resection for colon cancer

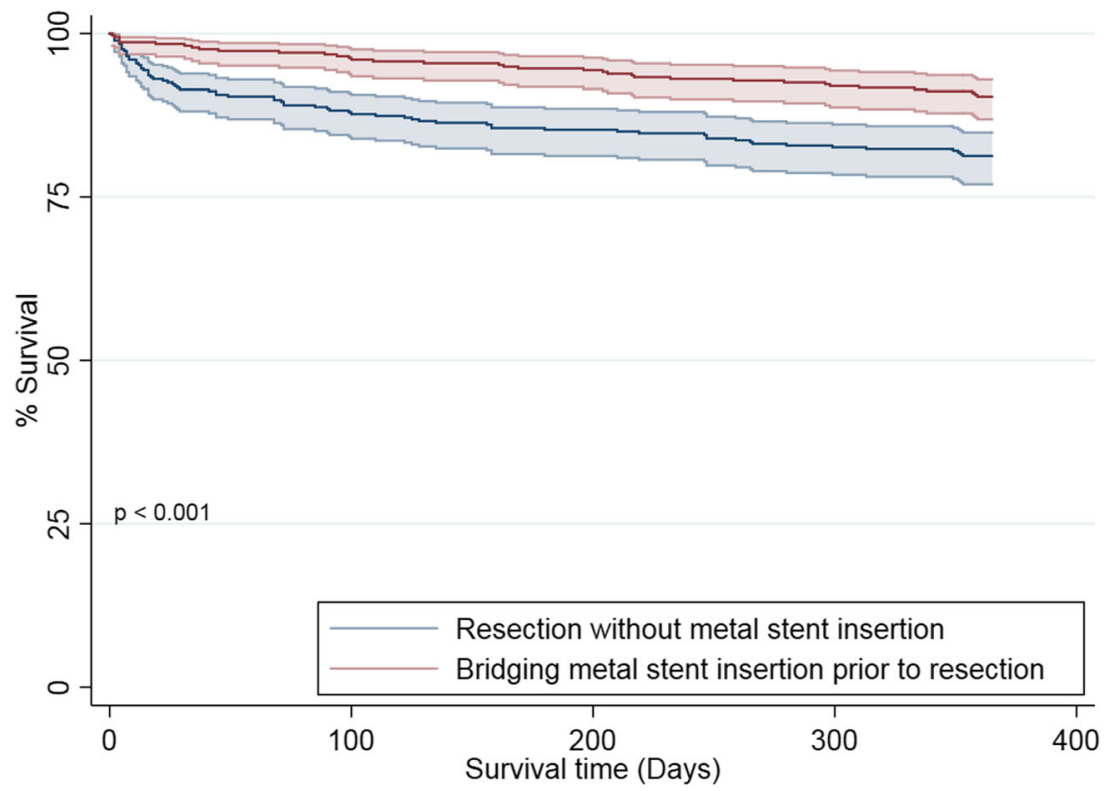


Table 3 Complications within 30 days of colon cancer resection in the whole study population and after propensity matching

\begin{tabular}{|c|c|c|c|c|c|c|}
\hline & \multicolumn{3}{|c|}{ Whole study population } & \multicolumn{3}{|c|}{ After propensity-matching } \\
\hline & $\begin{array}{l}\text { Surgery only } \\
(n=4170)\end{array}$ & $\begin{array}{l}\text { Metal stent } \\
(n=401)\end{array}$ & $p$ value & $\begin{array}{l}\text { Surgery only } \\
(n=375)\end{array}$ & $\begin{array}{l}\text { Metal stent } \\
(n=375)\end{array}$ & $p$ value \\
\hline \multicolumn{7}{|c|}{ Acute kidney injury } \\
\hline No & $4004(96.0)$ & $394(98.3)$ & \multirow[t]{2}{*}{0.025} & $362(96.5)$ & $368(98.1)$ & \multirow[t]{2}{*}{0.174} \\
\hline Yes & $166(4.0)$ & $7(1.8)$ & & $13(3.5)$ & $7(1.9)$ & \\
\hline \multicolumn{7}{|c|}{ Anastomosis } \\
\hline No & 4105 (98.4) & $394(98.3)$ & \multirow[t]{2}{*}{0.774} & $367(97.9)$ & $368(98.1)$ & \multirow[t]{2}{*}{0.794} \\
\hline Yes & $65(1.6)$ & $7(1.8)$ & & $8(2.1)$ & $7(1.9)$ & \\
\hline \multicolumn{7}{|c|}{ Cardiovascular } \\
\hline No & $3814(91.5)$ & $376(93.8)$ & \multirow[t]{2}{*}{0.111} & $346(92.3)$ & $352(93.9)$ & \multirow[t]{2}{*}{0.388} \\
\hline Yes & $356(8.5)$ & $25(6.2)$ & & $29(7.7)$ & $23(6.1)$ & \\
\hline \multicolumn{7}{|c|}{ Colostomy complications } \\
\hline No & $4133(99.1)$ & $401(100)$ & \multirow[t]{2}{*}{0.072} & \multirow{2}{*}{$\underset{\mathrm{a}}{>} 369(>98.4)^{\mathrm{a}}$} & $375(100)$ & \multirow[t]{2}{*}{0.062} \\
\hline Yes & $37(0.9)$ & $0(0)$ & & & $0(0)$ & \\
\hline \multicolumn{7}{|c|}{ Respiratory } \\
\hline No & $3853(92.4)$ & \multirow{2}{*}{$\underset{\mathrm{a}}{>} 395(>98.5)^{\mathrm{a}}$} & \multirow{2}{*}{$<0.001$} & $347(92.5)$ & $>369(98.4)^{\mathrm{a}}$ & \multirow[t]{2}{*}{$<0.001$} \\
\hline Yes & $317(7.6)$ & & & $28(7.47)$ & & \\
\hline \multicolumn{7}{|l|}{ Sepsis } \\
\hline No & $3890(93.3)$ & $386(96.3)$ & \multirow[t]{2}{*}{0.021} & $353(94.1)$ & $361(96.3)$ & \multirow[t]{2}{*}{0.172} \\
\hline Yes & $280(6.7)$ & $15(3.7)$ & & $22(5.9)$ & $14(3.7)$ & \\
\hline \multicolumn{7}{|c|}{ Thrombosis } \\
\hline No & $4077(97.8)$ & \multirow{2}{*}{$\underset{\mathrm{a}}{>} 395(>98.5)^{\mathrm{a}}$} & \multirow[t]{2}{*}{0.044} & $367(97.9)$ & \multirow{2}{*}{$\underset{\mathrm{a}}{>} 369(>98.4)^{\mathrm{a}}$} & \multirow[t]{2}{*}{0.223} \\
\hline Yes & $93(2.2)$ & & & $8(2.1)$ & & \\
\hline \multicolumn{7}{|c|}{ Wound disruption } \\
\hline No & 4063 (97.4) & \multirow{2}{*}{$\underset{\mathrm{a}}{>} 395(>98.5)^{\mathrm{a}}$} & \multirow[t]{2}{*}{0.017} & $367(97.9)$ & \multirow{2}{*}{$\underset{\mathrm{a}}{>} 369(>98.4)^{\mathrm{a}}$} & \multirow[t]{2}{*}{0.223} \\
\hline Yes & $107(2.6)$ & & & $8(2.1)$ & & \\
\hline
\end{tabular}

${ }^{\text {a }}$ Indicates that the figure is $<6$. If a single figure is censured another will be marked as " $>$ " reflecting a value up to 5 points higher than that stated, to ensure the censured figure cannot be calculated coding to exclude any subject with metastatic disease and by only including those undergoing a resection intended to be curative, study subjects should only represent a narrow spectrum of tumour stages. Future studies would benefit from linkage to the national cancer registry, data including staging data, although this is not currently available under the terms of access to HES.

A systematic source of selection bias which could not be entirely corrected for derives from those subjects who are at higher operative risk. If surgery is performed initially, then they will be included in the present study. Should a MS be placed with bridging intent in such subjects, once the higher operative risk is fully assessed, the treatment plan may change to not include resection. Therefore in this analysis, the MS group will exclude some very high-risk subjects who do not proceed to resection compared to the surgery-only group.

Selective-survival bias will similarly impact on the results in that any subject who undergoes an intended bridging MS insertion but does not survive to resection will not be included in the MS group. Selection bias will be reduced by utilising propensity matched analysis. This method gives a propensity score to each subject based upon age at obstruction, gender, type of surgery and Charlson co-morbidity score. Subjects can then be matched carefully based on these parameters. In nonrandomised studies with large numerical and constitutional discrepancies between participant numbers per cohort, this technique allows close matching of the study groups. Furthermore, those without a suitable match are excluded. This will therefore reduce the potential for selection bias described above.

As a non-randomised study subject selection for bridging MS was by the treating physician. Therefore, there will be a potential bias towards those subjects in whom a MS is expected to give a good outcome. Propensity matching allows us to ameliorate this bias based upon measureable variables, but as noted above, some important variables, such as physiological status and tumour stage, are not available within HES.

Data validation represents a key challenge. Stent placement is a relatively uncommon event on an individual provider basis. It is even less common when used as a bridge to surgery. Therefore, local validation focused on all stents inserted for colorectal cancer. The use of national data sources to support validation is not feasible, as there are no comparable data sets including only subjects presenting with obstruction. Clinical 
trial data demonstrates comparable technical success of stent insertion to the present study. However, the pragmatic nature of the current study, including all subjects undergoing bridging stenting, provides a different subject cohort to that seen in clinical trials. Local provider and clinical trial data demonstrated good correlation with study data in the present study, supporting the validity of case identification and the results reported.

The coding of technical failure of colorectal MS insertion is challenging, as there is no nationally recognised nomenclature for how to code this and the same code as a successful stent may be employed. It was also not possible to discern between radiologic and endoscopic stent placement. Therefore, a procedural success rate for colorectal MS insertion cannot be accurately calculated. However, the close correlation between the number of subjects assumed to have failed MS insertion, as they required immediate resection, to the reported CREST, 2004 meta-analysis and 2014 meta-analysis MS insertion procedural success rates suggests this is a reasonable proxy for technical stent insertion failure.

In this, the largest study to date of colorectal MS as a bridge to surgery, compared with emergency surgery, a significant reduction in mortality for those undergoing MS was observed. Subjects undergoing MS insertion also had lower stoma rates, a higher incidence of laparoscopic surgery and a lower incidence of respiratory complications. Our study supports the hypothesis that bridging colorectal MS for subjects presenting with bowel obstruction are of benefit to patients, by potentially avoiding high-risk emergency surgery. Prospective randomised studies should focus on the opportunities provided by MS to optimise subjects prior to eventual curative resection.

Data are presented as median (IQR) or $n(\%)$

Acknowledgments The authors are grateful to Mr. Nigel Suggett (Consultant colorectal surgeon) for his assistance with data analysis.

Funding statement Internal funding only.

Disclosures The authors declare that they have no conflict of interest.

Open Access This article is distributed under the terms of the Creative Commons Attribution 4.0 International License (http:// creativecommons.org/licenses/by/4.0/), which permits unrestricted use, distribution, and reproduction in any medium, provided you give appropriate credit to the original author(s) and the source, provide a link to the Creative Commons license, and indicate if changes were made.

\section{References}

1. Bowel Cancer Statistics. Cancer Research UK

2. Phillips R, Hittinger R, Fry JS, Fielding LP (1985) Malignant large bowel obstruction. Br J Surg 72:296-302

3. Serpell J, McDermott FT, Katrivessis H, Hughes ES (1989) Obstructing carcinomas of the colon. Br J Surg 76(9):965-969

4. Ng HJ, Yule M, Twoon M, Binnie NR, Aly EH (2015) Current outcomes of emergency large bowel surgery. Ann R Coll Surg Eng1 97(2):151-156

5. Borowiec AM, Wang CS, Yong E, Law C, Coburn N, Sutradhar R et al (2016) Colonic stents for colorectal Cancer are seldom used and mainly for palliation of obstruction: a population-based study. Can J Gastroenterol Hepatol 2016:1945172

6. Zhao X, Liu B, Zhao E, Wang J, Cai M, Xia Z et al (2014) The safety and efficiency of surgery with colonic stents in left-sided malignant colonic obstruction: a meta-analysis. Gastroenterol Res Pract 2014:407325

7. Suen MK, Zahid A, Young JM, Rodwell L, Solomon MJ, Young CJ (2015) How to decide to undertake a randomized, controlled trial of stent or surgery in colorectal obstruction. Surgery. 157(6):11371141

8. Hospital Episode Statistics. NHS digital

9. Hill J, Kay C, Morton D, Magill L, Handley K, Gray RG 2016 CREST Trial Collaborative Group. CREST: Randomised phase III study of stenting as a bridge to surgery in obstructing colorectal cancer-Results of the UK ColoRectal Endoscopic Stenting Trial (CREST). J Clin Oncol :34, (suppl; abstr 3507)

10. Nuttal M, Van Der Meulen J, Emberton M (2006) Charlson scores based on ICD-10 adminsitrative data were valid in assessing comorbidity in patients undergoing urological encer surgery. J Clin Epidemiol 59:265-273

11. Crooks CJ, West J, Card TR (2015) A comparison of the recording of comorbidity in primary and secondary care by using the Charlson index to predict short-term and long-term survival in a routine linked data cohort. BMJ Open 5(6):e007974

12. 2015 Statacorp. Stata statistical software: release 14.: TX: StataCorp LP

13. Arezzo A, Balague C, Targarona E, Borghi F, Giraudo G, Ghezzo L, Arroyo A, Sola-Vera J, De Paolis P, Bossotti M, Bannone E, Forcignanò E, Bonino MA, Passera R, Morino M (2016) Colonic stenting as a bridge to surgery versus emergency surgery for malignant colonic obstruction: results of a multicentre randomised controlled trial (ESCO trial). Surg Endosc

14. Sebastian S, Johnston S, Geoghegan T, Torreggiani W, Buckley M (2004) Pooled analysis of the efficacy and safety of self-expanding metal stenting in malignant colorectal obstruction. Am J Gastroenterol 99(10):2051-2057

Publisher's note Springer Nature remains neutral with regard to jurisdictional claims in published maps and institutional affiliations. 